\title{
Correction to: Establishing Trust in the Illegal Wildlife Trade in China
}

\section{Daan P. van Uhm ${ }^{1} \cdot$ Rebecca W. Y. Wong ${ }^{2}$}

Published online: 10 July 2020

(C) Springer Nature B.V. 2020

\section{Correction to: Asian Journal of Criminology 14(1):23-40 \\ https://doi.org/10.1007/s11417-018-9277-x}

The funding information provided at the Acknowledgement section in the original article is inaccurate. It should read as follow:

"Support of an Early Career Scheme research grant (CityU 21607917) provided by the Hong Kong Research Grant Council (Rebecca W.Y. Wong)."

Publisher's Note Springer Nature remains neutral with regard to jurisdictional claims in published maps and institutional affiliations.

The online version of the original article can be found at https://doi.org/10.1007/s11417-018-9277-x

Daan P. van Uhm

d.p.vanuhm@uu.nl

1 Department of Criminal Law and Criminology, Utrecht University, Newtonlaan 231, 3584 $\mathrm{BH}$ Utrecht, The Netherlands

2 Department of Social and Behavioural Sciences, City University of Hong Kong, 83 Tat Chee Ave, Kowloon Tong, Hong Kong 